\title{
Article
}

\section{Does Statin Therapy Reduce the Risks of Mortality and Major Adverse Cardiac and Cerebrovascular Events in Young Adults with End-Stage Renal Disease? Population-Based Cohort Study}

\author{
Ya-Lien Cheng ${ }^{1,2,+}{ }^{+}$, Huang-Yu Yang $1,2,+\left(\mathbb{D}\right.$, Chao-Yi Wu ${ }^{3}$, Chung-Ying Tsai ${ }^{1}$, Chao-Yu Chen ${ }^{1,2}$, \\ Ching-Chung Hsiao ${ }^{1,2}$, Hsiang-Hao Hsu ${ }^{1,2}$, Ya-Chung Tian ${ }^{1,2}$ and Chieh-Li Yen ${ }^{1,2, *}$ \\ 1 Kidney Research Center, Department of Nephrology, Chang Gung Memorial Hospital, Linkou Branch, \\ Taoyuan 33305, Taiwan; yolien0205@gmail.com (Y.-L.C.); hyyang01@gmail.com (H.-Y.Y.); \\ cytsai0616@cgmh.org.tw (C.-Y.T.); Chaoyuclaire@gmail.com (C.-Y.C.); colinhua0123@gmail.com (C.-C.H.); \\ hsianghao@gmail.com (H.-H.H.); dryctian@cgmh.org.tw (Y.-C.T.) \\ 2 College of Medicine, Chang Gung University, Taoyuan 33305, Taiwan \\ 3 Division of Rheumatology, Allergy and Immunology, Chang Gung Memorial Hospital, \\ Taoyuan 33305, Taiwan; joywucgu@hotmail.com \\ * Correspondence: b9102087@yahoo.com.tw; Tel.: +886-975-367-240 \\ + These two authors contributed equally to the study and manuscript.
}

check for updates

Citation: Cheng, Y.-L.; Yang, H.-Y.; Wu, C.-Y.; Tsai, C.-Y.; Chen, C.-Y.; Hsiao, C.-C.; Hsu, H.-H.; Tian, Y.-C.; Yen, C.-L. Does Statin Therapy Reduce the Risks of Mortality and Major Adverse Cardiac and Cerebrovascular Events in Young Adults with End-Stage Renal Disease? Population-Based Cohort Study. J. Clin. Med. 2021, 10, 2097. https:// doi.org/10.3390/jcm10102097

Academic Editor:

Francesca Mallamaci

Received: 10 April 2021

Accepted: 10 May 2021

Published: 13 May 2021

Publisher's Note: MDPI stays neutral with regard to jurisdictional claims in published maps and institutional affiliations.

Copyright: () 2021 by the authors. Licensee MDPI, Basel, Switzerland. This article is an open access article distributed under the terms and conditions of the Creative Commons Attribution (CC BY) license (https:// creativecommons.org/licenses/by/ $4.0 /)$.

\begin{abstract}
Among hemodialysis patients aged more than 40 years old, previous large-scale studies showed statin treatment had no effect on reducing cardiovascular adverse events. However, youngadult-onset end-stage renal disease (ESRD) patients have different physicosocial factors compared to older ESRD patients. The benefit of statins in such a specific group has not been well evaluated. Through the use of Taiwan's National Health Insurance Research Database (NHIRD), young adult patients aged 20-40 with incident ESRD requiring permanent dialysis between 1 January 2003 and 31 December 2015 were identified. The enrollees were further divided into two groups depending on whether they received statin therapy for more than 90 days (statin group) or never received any statin (nonstatin group) in the first year after initiation of dialysis. Propensity score weighting (PSW) was used to balance the baseline characteristics between the two groups. After PSW, the statin group $(n=771)$ exhibited a higher rate of major adverse cardiac and cerebrovascular events (MACCEs) (2.65\% vs. $1.44 \%$, hazard ratio (HR): 1.87, 95\% confidence interval (CI): 1.43-2.45), and acute myocardial infarction (1.51\% vs. $0.30 \%$, HR: $5.34,95 \%$ CI: $3.40-8.39$ ) compared to the nonstatin group $(n=1709)$. The risk of all-cause mortality, cardiovascular $(\mathrm{CV})$ death. and stroke did not significantly differ between the two groups. Similar to older patients, this study demonstrated that statin therapy cannot offer any protective effects in reducing CV outcomes among young adult ESRD patients undergoing dialysis.
\end{abstract}

Keywords: statin; dialysis; ESRD; young adult; cardiovascular

\section{Introduction}

Considerable research has confirmed that statins can considerably reduce the incidence of major adverse cardiovascular events and risk of mortality in high-risk patients, such as those with hyperlipidemia and diabetes [1-5]. Statins offer significant cardiovascular (CV) benefits by effectively reducing circulating low-density lipoprotein (LDL) cholesterol through the inhibition of hepatic hydroxymethylglutaryl (HMG) coenzyme A $(\mathrm{CoA})$ reductase, leading to the stabilization or even regression of atherosclerotic plaque. However, several large-scale randomized controlled trials on statin treatment [6-8] and high-quality meta-analyses [9] have reported that statin treatment did not provide significant CV protective effects in patients with end-stage renal disease (ESRD) as they did in traditional high-risk groups despite their marked LDL-cholesterol-lowering ability. This lack of CV benefit has been attributed to long-term comorbidities, such as diabetic 
vasculopathy and hyperlipidemia in early chronic kidney disease (CKD). These chronic vascular conditions are often irreversible and cannot be improved by statin treatment during ESRD $[10,11]$. CV mortality among the ESRD population has also been primarily attributed to nonatherosclerosis $\mathrm{CV}$ events, such as arterial calcification due to hyperphosphatemia and hypercalcemia and left ventricular hypertrophy (LVH) due to poor fluid control after dialysis initiation. These nonatherosclerosis $\mathrm{CV}$ events respond poorly to statin-induced LDL reduction [11-14]. However, why statin treatment fails to provide benefits in patients with ESRD remains unclear.

Most previous studies enrolled only older patients with ESRD. The 4D study recruited patients with ESRD aged 18 to 80 years, with an average age of 65.7 years [6]. The AURORA and SHARP studies recruited patients receiving dialysis aged 50 to 80 and $>40$ years, respectively $[7,8]$. Young adults with ESRD have been reported to demonstrate distinct characteristics in the incidence and prevalence of chronic illnesses. In a retrospective study, compared with older patients, young adults with ESRD often had a shorter duration of pre-existing, non-dialysis-requiring CKD prior to ESRD, resulting in a lower CV disease burden over time [15]. Moreover, the ESRD etiology, comorbidities, and performance status of younger patients receiving dialysis are different from those of older patients $[16,17]$. According to epidemiological studies, glomerulonephropathy, hypertension, genetic and metabolic diseases, and congenital anomalies of the kidney and urinary tract-rather than diabetes, tumor, nephrolithiasis, or other chronic systemic diseases-are the leading causes of ESRD in young adults $[18,19]$. However, the CV mortality rates of younger and older patients receiving dialysis are similar. Nearly $40 \%$ of deaths were attributable to CV causes among young adults aged 22 to 29 years with incident ESRD $[15,20]$. The risk of CV mortality in young adults with incident ESRD is 143 to 500 times higher than that of agematched individuals in the general population [21]. Thus, potential treatment strategies to reduce the likelihood of $\mathrm{CV}$ events among this population are worth investigating.

Few studies on the clinical outcomes and efficacy of statin treatment in young adults with incident ESRD undergoing dialysis have been conducted. We assume that statin treatment may provide significant benefits in young adults with ESRD because they have not yet been affected by aging, have fewer systemic chronic illnesses, and have a shorter duration of the CKD burden. In this study, we employed Taiwan's National Health Insurance (NHI) Research Database (NHIRD), which contains nationwide populationbased information, to determine whether statins can reduce the mortality and major adverse cardiac and cerebrovascular event (MACCE) risks in patients aged between 20 and 40 years with ESRD and requiring permanent dialysis.

\section{Materials and Methods}

\subsection{Data Source}

Patient data were obtained from Taiwan's NHIRD. In 1995, Taiwan launched the NHI program, a nationwide, single-payer, compulsory health care system covering approximately $99.8 \%$ of Taiwan's population (nearly 23.37 million) since 1997. The NHIRD contains comprehensive information about insured patients' health care, including disease diagnoses, outpatient visits, hospitalizations, procedures, medication prescriptions, and specific conditions. The diagnosis of diseases in the NHIRD is based on the International Classification of Diseases, 9th Revision, Clinical Modification (ICD-9-CM) before 2015 and ICD-10-CM since 2016. Detailed records of drug prescriptions and procedure interventions and the comprehensiveness of the database, given that it covers an entire population, are the two main advantages of the NHIRD. However, the database does not contain laboratory data or examination reports. More information about the NHI program and NHIRD can be obtained from previous studies [22,23]. Before releasing data to researchers, any information in the database that can identify a particular patient or health care provider is encrypted to ensure privacy. This study was approved by the institutional review board of the Chang Gung Medical Foundation (Approval Number: 202100150B1). 


\subsection{Study Design}

We used data from the NHIRD to evaluate the association of mortality and CV events with the use of statins after dialysis initiation in young patients (age, 20-40 years) with ESRD. As shown in Figure 1, patients with newly diagnosed ESRD between 20 and 40 years of age and receiving dialysis treatment between 2003 and 2015 were identified. The 365th day after the start of dialysis was defined as the index date. Patients with a history of malignancy or MACCEs before the index date and patients who ended dialysis treatment (died or received kidney transplantation) between the start of hemodialysis and the index dates were excluded. Considering that the diet habit and long-term medications in patients with incident ESRD are gradually established over several months after commencing dialysis, we categorized all participants into two groups depending on whether they received any type of statin therapy for more than 90 days (statin group) or never received any statins (nonstatin group) in the first year after dialysis initiation. The follow-up period was from the index date (365th day after dialysis initiation) to the date of death, successful kidney transplantation, the independent occurrence of any of the study outcomes, or the end date of the study period (31 December 2017), whichever occurred first.

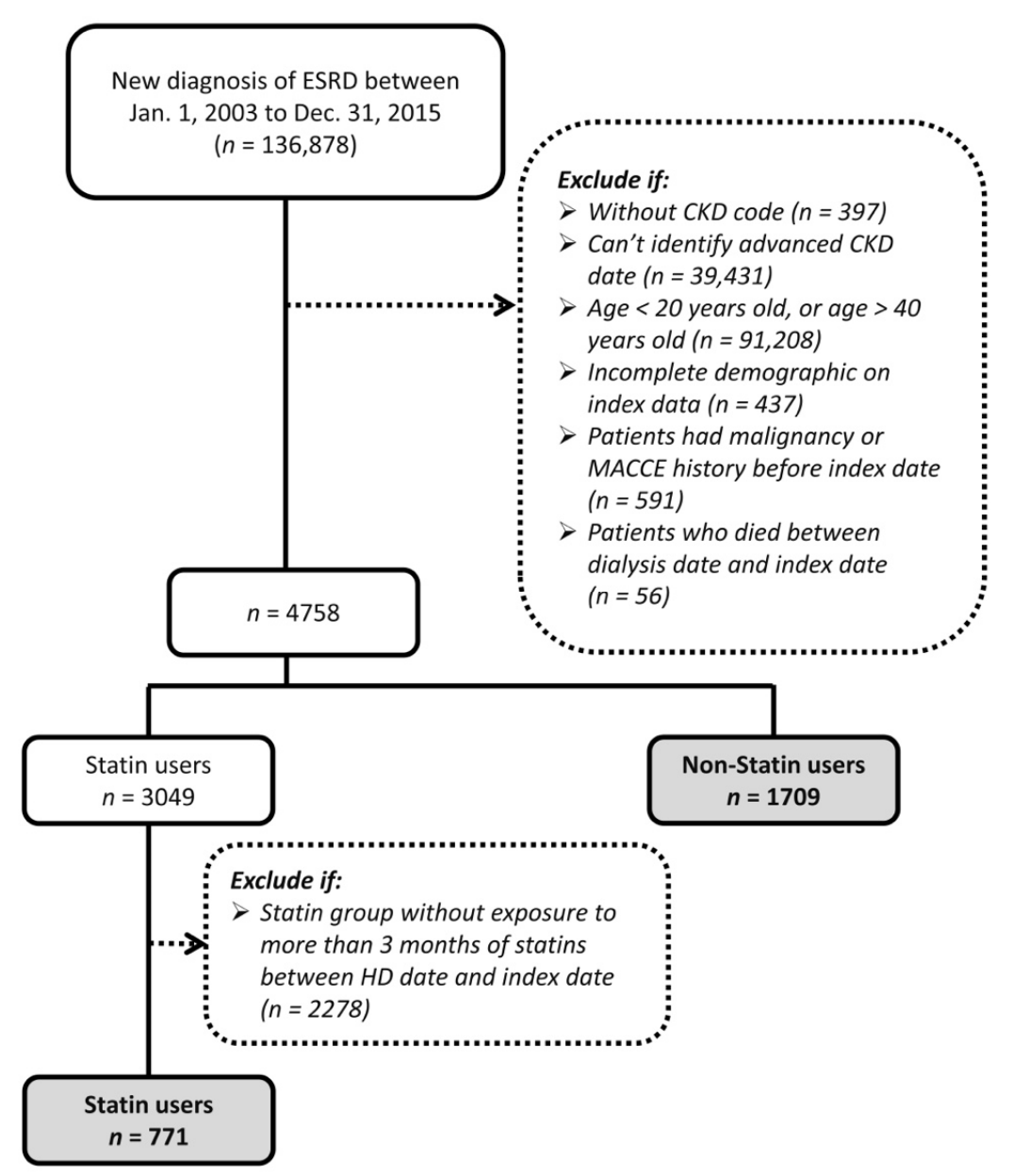

Figure 1. Flowchart showing the patient selection process.

\subsection{Covariates and Outcomes}

The covariates in this study were age; sex; income level; residential urbanization level; comorbidities; Charlson comorbidity index (CCI) [24]; index date; frequency of hospitalization and outpatient visits, which may partially represent the patient's health status; and medications. Comorbidities were determined if they were reported for more than two outpatient visits or one inpatient stay in the year before the index date. Medications were 
identified if a patient had received a prescription for more than 3 months between the dialysis and index dates.

We focused on the outcomes of all-cause mortality and MACCEs, which were defined as the composite of myocardial infarction, cardiogenic shock, new-onset heart failure, target vessel revascularization, malignant arrhythmia, stroke, and CV events. All-cause mortality was defined as the patient's name appearing in the Taiwan Death Registry. Early death within the first year after dialysis initiation was mainly attributed to baseline comorbidities or nutritional status rather than receipt of statin treatment. Therefore, in this study, we only compared the results of interest in patients who underwent dialysis for more than 1 year, and the observation period began on the 365th day after dialysis initiation. MACCEs were diagnosed on the basis of the principal diagnosis upon hospitalization or during the emergency department visit. Diagnostic codes were ICD-9 codes before 2015 or ICD-10 codes from 2016 (Supplementary Materials Table S1), and most of them have codes been validated previously $[25,26]$.

\subsection{Statistical Analysis}

Propensity score weighting was performed to simulate a randomized clinical trial by balancing baseline characteristics between study groups (statin and nonstatin groups). PSWs preserve the sample size of the original data, providing an appropriate estimate of the variation in the main impact and maintaining the specified type I error [27]. PSWs in the study groups were obtained using the generalized boosted model (GBM), which can automatically determine the best functions of covariates, including interactions or polynomial terms, to achieve the optimal balance in the study groups. Moreover, PSWs obtained using the GBM are not strongly affected by large weights [28].

All covariates listed in Table 1 were included in the GBM, except for the CCI, which was already a combination of other covariates. The absolute standardized mean difference (ASMD) rather than statistical tests was used to assess the balance of potential confounders between the groups at baseline (index date) because the balance is an attribute of the sample and not of the underlying population. ASMD $\leq 0.1$ indicated that the difference in potential confounding factors between the groups was not significant, whereas ASMD $<0.2$ indicated a small difference between the groups [28,29].

Table 1. Baseline characteristics of the study population before and after PSW matching.

\begin{tabular}{|c|c|c|c|c|c|c|}
\hline & \multicolumn{3}{|c|}{ Before PSW } & \multicolumn{3}{|c|}{ After PSW } \\
\hline & $\begin{array}{l}\text { Statin Users } \\
\quad(n=771)\end{array}$ & $\begin{array}{c}\text { Nonstatin } \\
\text { Users } \\
(n=1709)\end{array}$ & ASMD & $\begin{array}{l}\text { Statin Users } \\
\quad(n=635)\end{array}$ & $\begin{array}{c}\text { Nonstatin } \\
\text { Users } \\
(n=1601)\end{array}$ & ASMD \\
\hline Age (years) & $33.81 \pm 5.03$ & $32.89 \pm 5.67$ & 0.1713 & $33.42 \pm 4.72$ & $33.1 \pm 5.33$ & 0.0645 \\
\hline Male, $n(\%)$ & $300(38.91)$ & $990(57.93)$ & 0.3876 & $289(45.56)$ & $850(53.08)$ & 0.1509 \\
\hline $\mathrm{Urb}, n(\%)$ & & & 0.1439 & & & 0.0493 \\
\hline Urban & $221(28.66)$ & $431(25.22)$ & & $180(28.36)$ & $416(25.96)$ & \\
\hline Suburban & $257(33.33)$ & $519(30.37)$ & & $196(30.98)$ & $495(30.94)$ & \\
\hline Rural & $293(38.00)$ & $759(44.41)$ & & $258(27.19)$ & $690(43.10)$ & \\
\hline Occupation, $n(\%)$ & & & 0.1245 & & & 0.0958 \\
\hline Dependent & $80(10.38)$ & $230(13.46)$ & & $72(11.32)$ & $202(12.62)$ & \\
\hline Civil servants & $20(2.59)$ & $47(2.75)$ & & $15(2.37)$ & $43(2.68)$ & \\
\hline Nonmanual worker & $230(29.83)$ & $444(25.98)$ & & $181(28.37)$ & $436(27.26)$ & \\
\hline Manual worker & $256(33.20)$ & 549 (32.12) & & $202(31.85)$ & $514(32.10)$ & \\
\hline Other & $185(23.99)$ & $439(25.69)$ & & $163(25.83)$ & $406(25.34)$ & \\
\hline Income (NTD), $n(\%)$ & & & 0.2232 & & & 0.0777 \\
\hline Dependent & $80(10.38)$ & $230(13.46)$ & & $72(11.32)$ & $202(12.62)$ & \\
\hline$<17,280$ & $219(28.40)$ & $556(32.53)$ & & $195(30.70)$ & $513(32.08)$ & \\
\hline $17,280-21,008$ & $156(20.23)$ & $374(21.88)$ & & $136(21.52)$ & $338(21.13)$ & \\
\hline $21,009-33,229$ & $187(24.25)$ & $336(19.66)$ & & $136(21.52)$ & $328(20.48)$ & \\
\hline$>33,300$ & $129(16.73)$ & $213(12.46)$ & & $95(14.94)$ & $219(13.69)$ & \\
\hline Comorbidities, $n(\%)$ & & & & & & \\
\hline
\end{tabular}


Table 1. Cont.

\begin{tabular}{|c|c|c|c|c|c|c|}
\hline & \multicolumn{3}{|c|}{ Before PSW } & \multicolumn{3}{|c|}{ After PSW } \\
\hline & $\begin{array}{l}\text { Statin Users } \\
\quad(n=771)\end{array}$ & $\begin{array}{c}\text { Nonstatin } \\
\text { Users } \\
(n=1709)\end{array}$ & ASMD & $\begin{array}{l}\text { Statin Users } \\
\quad(n=635)\end{array}$ & $\begin{array}{c}\text { Nonstatin } \\
\text { Users } \\
(n=1601)\end{array}$ & ASMD \\
\hline Atrial fibrillation & $0(0.00)$ & $3(0.18)$ & 0.0593 & $0(0.00)$ & $4(0.23)$ & 0.0674 \\
\hline Chronic pulmonary disease & $20(2.59)$ & $35(2.05)$ & 0.0363 & $15(2.30)$ & $32(1.97)$ & 0.0228 \\
\hline Connective tissue disease & $94(12.19)$ & $140(8.19)$ & 0.1325 & $66(10.42)$ & $148(9.27)$ & 0.0386 \\
\hline Diabetes mellitus & $299(38.78)$ & $185(10.83)$ & 0.6841 & $135(21.34)$ & $259(16.15)$ & 0.1332 \\
\hline Heart failure & $39(5.06)$ & $96(5.62)$ & 0.0249 & $28(4.43)$ & $84(5.23)$ & 0.0370 \\
\hline Hypertension & $582(75.49)$ & $1019(59.63)$ & 0.3438 & $435(68.62)$ & $1013(63.29)$ & 0.1125 \\
\hline Liver cirrhosis & $3(0.39)$ & $29(1.70)$ & 0.1290 & $<3(<0.45)$ & $22(1.36)$ & 0.1290 \\
\hline Peripheral arterial disease & $7(0.91)$ & $26(1.52)$ & 0.0560 & $4(0.65)$ & $21(1.31)$ & 0.0674 \\
\hline Polycystic kidney disease & $5(0.65)$ & $22(1.29)$ & 0.0653 & $9(1.39)$ & $18(1.13)$ & 0.0234 \\
\hline $\begin{array}{l}\text { Charlson comorbidity index, } \\
\text { Medications, } n(\%)\end{array}$ & $2.25 \pm 1.1$ & $1.88 \pm 0.98$ & 0.3592 & $1.99 \pm 0.91$ & $1.94 \pm 0.96$ & 0.0580 \\
\hline$\overline{\mathrm{ACEi} / \mathrm{ARB}}$ & $438(56.81)$ & $592(34.64)$ & 0.4565 & $287(45.21)$ & $634(39.58)$ & 0.1141 \\
\hline Other anti-HTN & $598(77.56)$ & $845(49.44)$ & 0.6107 & $398(62.76)$ & $900(56.24)$ & 0.1331 \\
\hline Aspirin/Plavix & $64(8.30)$ & $58(3.39)$ & 0.2103 & $30(4.81)$ & $58(3.63)$ & 0.0586 \\
\hline Insulin & $151(19.58)$ & $73(4.27)$ & 0.4862 & $64(10.12)$ & $111(6.96)$ & 0.1131 \\
\hline $\mathrm{OHA}$ & $123(15.95)$ & $49(2.87)$ & 0.4599 & $50(7.81)$ & $73(4.59)$ & 0.1339 \\
\hline $\begin{array}{c}\text { No. of outpatient visits in the } \\
\text { previous year }\end{array}$ & $33.68 \pm 14.70$ & $29.51 \pm 12.40$ & 0.3061 & $31.00 \pm 11.69$ & $30.32 \pm 12.38$ & 0.0562 \\
\hline $\begin{array}{l}\text { Hospitalizations in the } \\
\text { previous year, } n(\%)\end{array}$ & $339(43.90)$ & $639(37.97)$ & 0.1342 & $257(40.60)$ & $620(38.72)$ & 0.0384 \\
\hline
\end{tabular}

PSW, propensity score weighting; ASMD, absolute standardized mean difference; ACEi/ARB, angiotension converting enzyme inhibitor/angiotension receptor blocker; HTN, hypertension; OHA, oral hypoglycemic agent.

The incidence was calculated by dividing the total number of study results during the follow-up period by person-years at risk. The all-cause and CV mortality risks of the groups were compared using the Kaplan-Meier curve for univariate analysis and Cox proportional hazards model for multivariate analysis. The risks of MACCEs, acute myocardial infarction (AMI), and stroke were evaluated using competing risk analysis (subdistribution hazard function and cumulative incidence function) in which death during the follow-up period was regarded as a competing risk. We plotted the Kaplan-Meier curve for time to event outcomes. PSWs were re-estimated for each subgroup analysis to maintain a balance of covariates between the groups. $p<0.05$ indicated statistical significance. All statistical analyses were performed using SAS 9.4 (SAS Institute Inc., Cary, NC, USA).

\section{Results}

\subsection{Patient Characteristics}

Data of 4758 young patients (age, 20-40 years) with new-onset ESRD receiving hemodialysis between 2003 and 2015 and who had ever received a diagnosis of dyslipidemia were extracted from the NHIRD (Figure 1). Of the patients, 771 had received statin therapy for more than 90 days between the dialysis initiation and index dates, and 1709 had never received any statin treatment. Those who received statin treatment less than 90 days were excluded. The baseline characteristics of the groups are presented in Table 1. The statin group had more female patients, patients with higher income, higher prevalence of hypertension and diabetes, higher comorbidity scores, greater use of certain medications (i.e., angiotensin-converting enzyme inhibitors or angiotensin receptor blockers, antihypertensive agents, aspirin (Plavix), insulin, and oral hypoglycemic agents), frequent outpatient visits, and higher probability of hospitalization than the nonstatin group before the PSW matching. After the PSW matching, most ASMD values were less than 0.1 , and all ASMD values were less than 0.2 , indicating that the clinical characteristics of the groups were well balanced. 


\subsection{Outcomes}

We aimed to assess whether statin treatment affects long-term outcomes in young patients with ESRD receiving permanent dialysis. The long-term outcomes are listed in Table 2. The statin group demonstrated a higher rate (per person-years) of MACCEs ( $2.65 \%$ vs. $1.44 \%$, hazard rate (HR): $1.87,95 \%$ confidence interval (CI): $1.43-2.45$ ) and AMI (1.51\% vs. $0.3 \%$, HR: $5.34,95 \%$ CI: $3.4-8.39)$ than the nonstatin group. The risk of all-cause mortality (1.96\% vs. $2.28 \%$, HR: $0.87,95 \%$ CI: $0.66-1.14)$, CV mortality $(0.23 \%$ vs. $0.17 \%$, HR: $1.33,95 \%$ CI: $0.57-3.08)$, and stroke (0.46\% vs. $0.70 \%$, HR: $0.66,95 \%$ CI: $0.39-1.14) \mathrm{did}$ not differ between the groups. The cumulative incidence of MACCEs, AMI, stroke, and CV and all-cause mortality is presented in Figure 2.

(A)

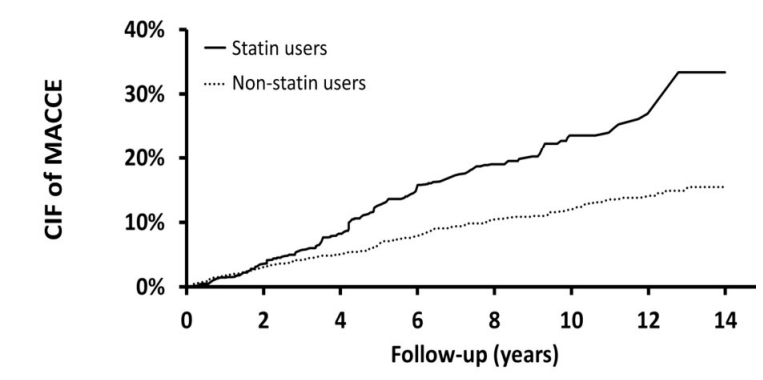

Number at risk

$\begin{array}{llllllll}\text { Statin users } & 634 & 487 & 346 & 242 & 156 & 72 & 32\end{array}$

$\begin{array}{llllllll}\text { Non-statin users } & 1601 & 1311 & 1017 & 723 & 497 & 329 & 216\end{array}$

(C)

Stroke

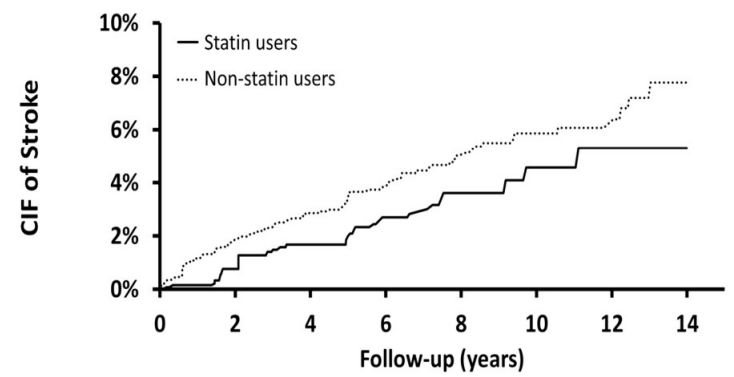

Number at risk

$\begin{array}{llllllll}\text { Statin users } & 634 & 525 & 394 & 266 & 203 & 97 & 63\end{array}$

$\begin{array}{llllllll}\text { Non-statin users } & 1601 & 1322 & 1034 & 760 & 527 & 381 & 292\end{array}$
(B)

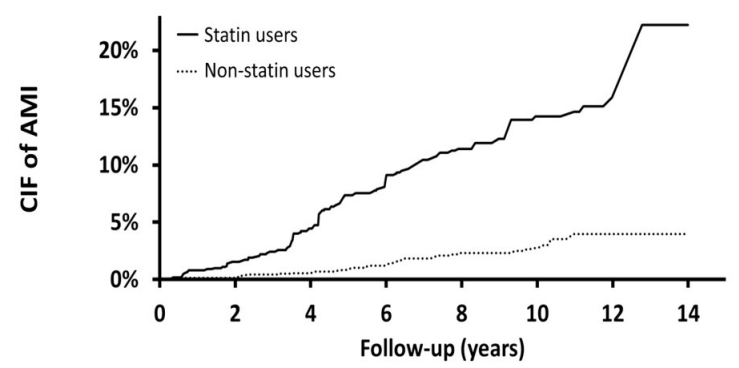

(D)

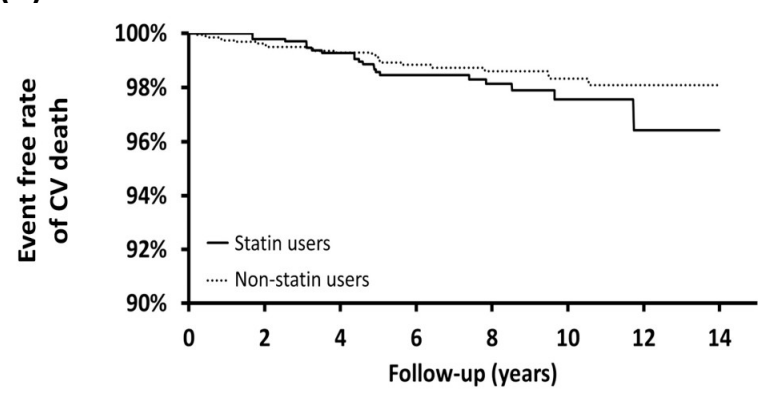

Number at risk

$\begin{array}{llllllll}\text { Statin users } & 634 & 492 & 368 & 269 & 181 & 93 & 43\end{array}$

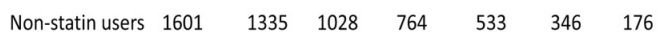

(E)

All-cause mortality

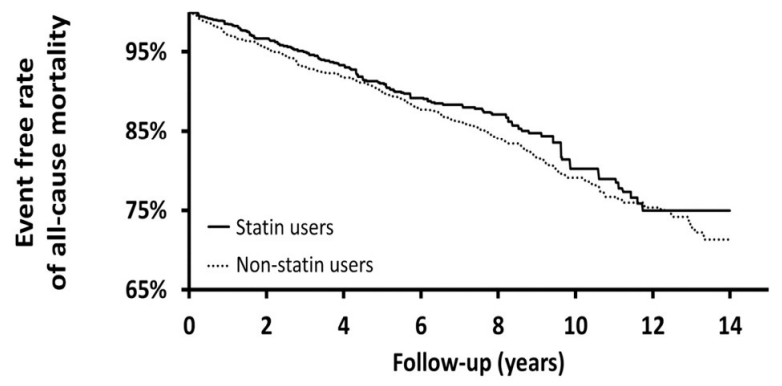

Number at risk

$\begin{array}{llllllll}\text { Statin users } & 634 & 492 & 368 & 269 & 181 & 93 & 43\end{array}$

$\begin{array}{llllllll}\text { Non-statin users } & 1601 & 1335 & 1028 & 764 & 533 & 346 & 176\end{array}$

Figure 2. Cumulative incidence of (A) major cardiac and cerebrovascular events (MACCEs), (B) acute myocardial infarction [30], (C) stroke, (D) cardiovascular (CV) death, and (E) all-cause mortality. CIF: cumulative incidence function. 
Table 2. Follow-up outcomes of young adult patients with ESRD according to their use of statins.

\begin{tabular}{|c|c|c|c|c|c|c|c|}
\hline & \multicolumn{3}{|c|}{ Statin Users } & \multicolumn{3}{|c|}{ Nonstatin Users } & \multirow{2}{*}{$\begin{array}{c}\text { Statin Users vs. } \\
\text { Nonstatin Users }\end{array}$} \\
\hline & $\begin{array}{l}\text { No. of } \\
\text { Event }\end{array}$ & Person-Years & $\begin{array}{c}\text { Incidence } \\
\text { Rate }\end{array}$ & $\begin{array}{l}\text { No. of } \\
\text { Event }\end{array}$ & Person-Years & $\begin{array}{c}\text { Incidence } \\
\text { Rate }\end{array}$ & \\
\hline MACCE $^{a}$ & 87 & 3263.61 & $\begin{array}{c}2.65 \\
(2.09-3.21)\end{array}$ & 138 & 9608.12 & $\begin{array}{c}1.44 \\
(1.20-1.68)\end{array}$ & $1.87(1.43-2.45) ;<0.0001$ \\
\hline AMI & 51 & 3376.31 & $\begin{array}{c}1.51 \\
(1.09-1.92)\end{array}$ & 30 & 9940.81 & $\begin{array}{c}0.30 \\
(0.19-0.41)\end{array}$ & $5.34(3.40-8.39) ;<0.0001$ \\
\hline Stroke & 16 & 3475.96 & $\begin{array}{c}0.46 \\
(0.24-0.69)\end{array}$ & 68 & 9815.81 & $\begin{array}{c}0.70 \\
(0.53-0.86)\end{array}$ & $0.66(0.39-1.14) ; 0.1368$ \\
\hline CV death & 8 & 3524.99 & $\begin{array}{c}0.23 \\
(0.10-0.44)\end{array}$ & 17 & $10,025.6$ & $\begin{array}{c}0.17 \\
(0.09-0.25)\end{array}$ & $1.33(0.57-3.08) ; 0.5132$ \\
\hline $\begin{array}{l}\text { All-cause } \\
\text { mortality }\end{array}$ & 69 & 3524.99 & $\begin{array}{c}1.96 \\
(1.50-2.42)\end{array}$ & 229 & $10,025.6$ & $\begin{array}{c}2.28 \\
(1.99-2.58)\end{array}$ & $0.87(0.66-1.14) ; 0.3058$ \\
\hline
\end{tabular}

a: Any of myocardial infarction, cardiogenic shock, new-onset heart failure, malignant arrhythmia, and cerebrovascular events; AMI: acute myocardial infarction; CI: confidence interval; CV: cardiovascular; HR: hazard ratio; SHR: subdistribution hazard ratio.

In order to avoid that the results of IPTW were largely affected by the data of patients with high weights, we have further adopted propensity score matching (PSM) to adjust (Supplementary Materials Table S2). After PSM, 619 people remained in the case and control groups, respectively. The result of the analysis is similar to the result of using the IPTW method, and the statin group still demonstrated a higher rate (per person-years) of MACCEs (2.73\% vs. $1.53 \%$, hazard rate (HR): $1.82,95 \%$ confidence interval (CI): $1.29-2.58)$ and AMI (1.50\% vs. $0.37 \%$, HR: $4.16,95 \%$ CI: $2.26-7.66)$ than the nonstatin group.

\subsection{Subgroup Analysis}

To determine whether the benefits of statin therapy were only seen in specific clinical conditions, we further conducted subgroup analysis of all-cause mortality and MACCE risk (Figure 3). Regarding all-cause mortality, statin therapy appeared to only have a protective effect in patients who were not taking any other antihypertensive drugs (HR: $0.33,95 \%$ CI: $0.15-0.73, p=0.0058$ ); no significant difference was noted in other subgroups. Regarding MACCEs, the MACCE risk was higher in the statin group than in the nonstatin group except for the subanalyses of patients with diabetes and those not using other antihypertensive agents. The CIs displayed in the forest plots are wide, implying that the subgroup analyses were limited by the relatively small number of enrollees. 


\section{(A) All-cause mortality}

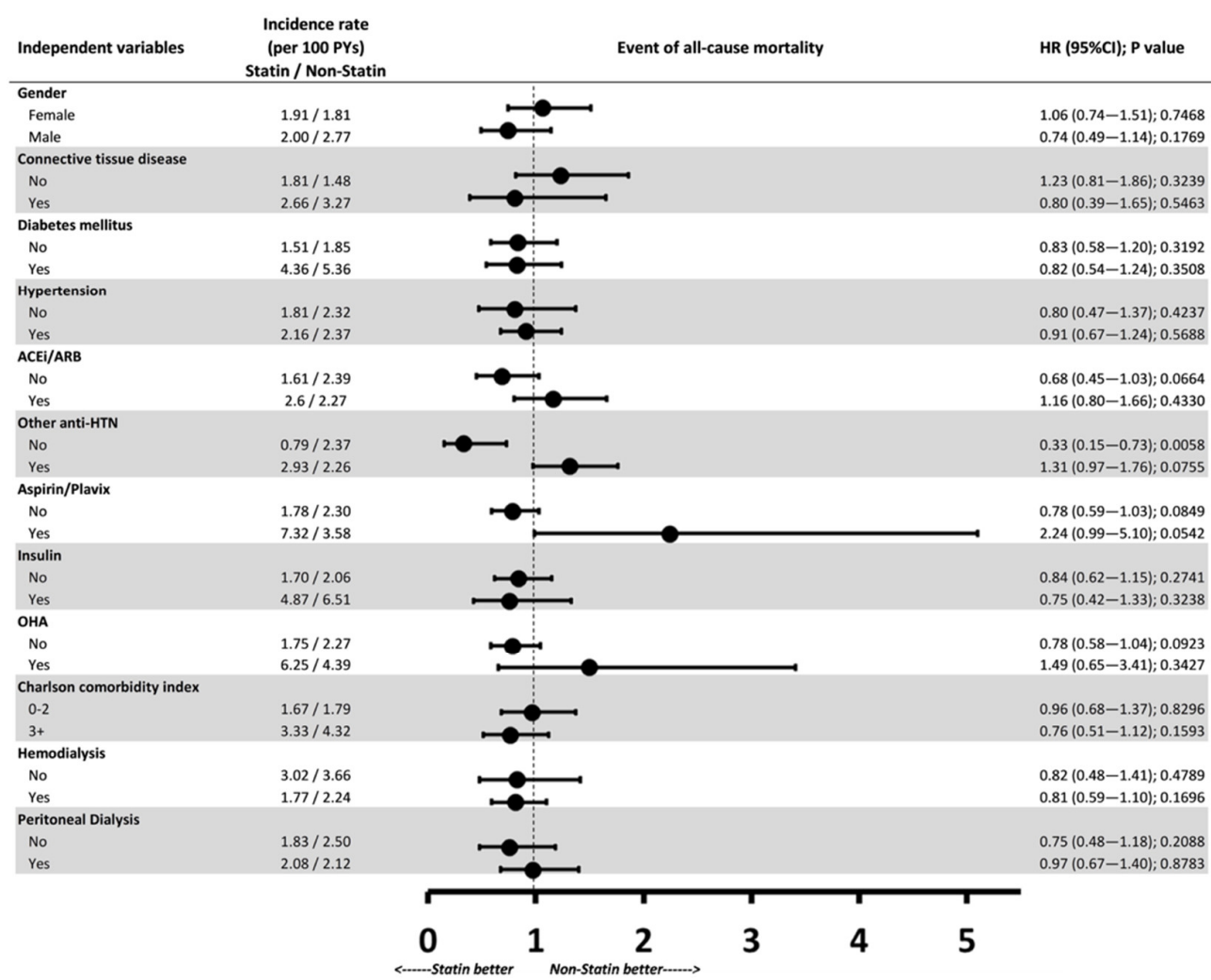

\section{(B) MACCES}

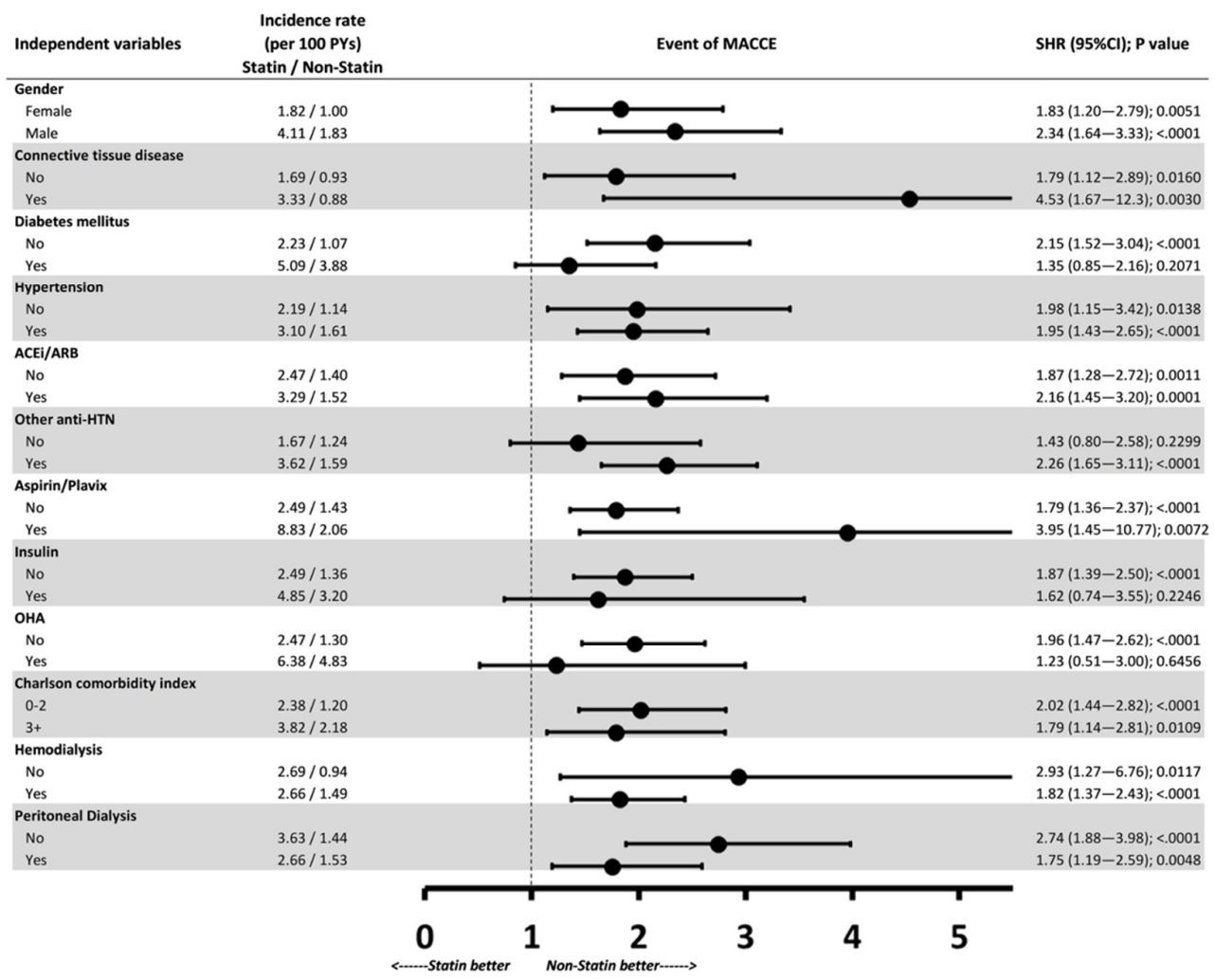

Figure 3. Subgroup analysis of (A) all-cause mortality and (B) MACCEs. PYs: person-years; HR: hazard ratio; SHR: subdistribution hazard ratio. 


\section{Discussion}

The lack of benefits of statin therapy in patients receiving dialysis has been widely discussed. Experts argue that the lack of benefits can be attributed to long-term multiple comorbidities in the ESRD population and delayed initiation of statin treatment. However, the major finding of this 14-year retrospective cohort study, which analyzed data from a comprehensive nationwide database, is that lipid-lowering statin therapy fails to reduce the risks of MACCEs and all-cause and CV mortality even in young patients with ESRD, few comorbidities, and no history of MACCEs. The counterintuitive result of this study may complete the missing part of previous randomized controlled trials evaluating statin treatment after dialysis initiation and provide clinical evidence for better understanding the pathophysiology of CV events in ESRD populations.

By applying PSW to balance any possible confounders such as age, sex, hospitalization frequency, diabetes mellitus, hypertension, $\mathrm{CCI}$, and commonly used medications, we demonstrated that compared with statin nonuse, statin use is associated with higher MACCE probability without reducing CV or all-cause mortality. The potential explanation for the disappointing finding is the different $\mathrm{CV}$ disease pathophysiologies in patients receiving dialysis compared with the general population. Importantly, the influences of mineral and bone metabolism disorder, volume overload, and control of hypertension may outweigh the importance of LDL level and atherosclerosis. First, studies have proven that higher average serum phosphorus concentration and daily calcium intake in patients receiving dialysis are related to coronary artery calcification and coronary artery disease [10,31]. In young adults, the imbalance of serum calcium and phosphate may be more severe than in older patients because of possible noncompliance with diet restrictions [32,33]. Atkinson et al. reported that fewer than one-quarter of young adults (age,18-24 years) could achieve the Kidney Disease Outcomes Quality Initiative (KDOQI)-recommended serum phosphorus and calcium levels [32]. Goodman et al. highlighted that the prevalence of coronary artery calcification, as measured using electron beam computed tomography, was as high as $88 \%$ among young patients (age, 20-30 years) receiving dialysis [31]. Second, in the young ESRD population, fluid restriction is another critical concern, and previous studies have reported their large fluid reduction during dialysis compared with older populations [33,34]. Repeated myocardial stunning induced by large fluid reduction during dialysis may eventually result in sudden CV death. Lastly, along with fluid overload and poor compliance with treatment regime, hypertension is the leading comorbidity in the younger population [20,35]. Importantly, compared with older patients with ESRD, who typically have multiple comorbidities, our study participants had considerably higher prevalence of hypertension than prevalence of other chronic diseases. Statin treatment cannot correct complications associated with long-term, poorly controlled hypertension, such as LVH and arrhythmias. In a database study, it is difficult to comprehensively analyze all factors due to a lack of detailed information, such as diet habits, fluid reduction during dialysis, and calcium and phosphate balance. However, we found that statin treatment could not ameliorate the nonatherosclerotic $\mathrm{CV}$ risks in the ESRD population, resulting in a similar mortality rate between the statin and nonstatin groups.

The higher MACCE and AMI risks in this study's statin group could not be explained and can be considered a chance finding. In an observational study of patients receiving renal replacement therapy, statin use was associated with a higher baseline coronary artery calcification (CAC) score (regardless of age, sex, and diabetes) and faster progression of the CAC score compared with no statin use in a longitudinal evaluation [30]. Moreover, several randomized studies involving patients without kidney disease have demonstrated that statins promote coronary atheroma calcification independent of their plaque-regressive effects, and which also did not correlate with a greater risk of CV events [36,37]. Statins change the composition of the coronary atheroma, thicken the fibrous cap, replace the central lipid pool with calcification and fibrosis, decrease plaque volume, and reduce inflammation [38,39]. These shifts in plaque components with increased calcium content stabilize vulnerable plaques, reducing the risk of rupture. However, the plaque-stabilizing 
effect of increased coronary artery calcification in the general population may not be considered benign in the ESRD dialysis population. In patients receiving dialysis, obvious calcium deposits in the vascular intimal and media layers and aortic and mitral valves are highly prevalent due to pathophysiological changes. The uremic vasculopathy and cardiomyopathy contribute to the excessively high mortality rate from cardiac causes. Overall, statin-induced calcification may aggravate the already severely elevated CV risk in the uremic milieu. Certain hypotheses regarding the procalcifying effect of statins have also been proposed recently. Statins not only lower lipid production by inhibiting HMG CoA reductase, the rate-controlling enzyme of the mevalonate pathway responsible for the synthesis of cholesterol and other isoprenoids but also impair vitamin $\mathrm{K} 2$ generation in vitro by affecting the metabolism of isoprenoids [30,40]. Vitamin $\mathrm{K}$ is essential for the activity of vascular calcification inhibitors such as matrix Gla28 protein. Compared with healthy individuals, patients receiving hemodialysis have poor overall vitamin $\mathrm{K}$ status due to low intake [41], and vitamin $\mathrm{K}$ supplementation has been proposed to arrest the progression of vascular calcification $[42,43]$. Thus, statins may accelerate vascular calcification in patients receiving dialysis by further depleting the vascular vitamin K2 level. Further studies are warranted to prove whether the procalcifying effect of statins abrogates the potential favorable effects of LDL cholesterol reduction in patients receiving dialysis.

This study has certain limitations. First, data for analysis were retrieved from the NHIRD, which does not contain laboratory information, including lipid profiles and levels of hemoglobin, creatinine, phosphate, calcium, and albumin. Although previous large-scale RCTs have proved the significant LDL-lowering effect of statin treatment. The lack of LDLcholesterol level information in NHIRD, which thus makes us unable to verify whether the statin group could truly achieve a lower LDL level than the nonstatin group, is the main limitation of this study. Further large-scale researches with comprehensive laboratory data are warranted to validate our findings. Second, although the PSW analysis included the most relevant confounders, all residual factors could not be eliminated because of the observational nature of the study, and this may have biased the results. Third, because of the number of enrollees and study design, evaluating the beneficial effect across different statin therapies and statin dosages was beyond the scope of this study.

\section{Conclusions}

In conclusion, statin therapy did not satisfactorily improve all-cause and CV mortality in young adults with ESRD receiving dialysis, even in those without a history of MACCEs. Therefore, we suggest prevention strategies-including lifestyle modification, exercise, dialysis therapy adherence, diet and fluid restriction, and early transplantation-instead of primarily focusing on lipid control to reduce the CV risk in young adults with ESRD.

Supplementary Materials: The following are available online at https://www.mdpi.com/article/10 .3390/jcm10102097/s1, Table S1: ICD9-code and ICD10-code used in this study; Table S2: Follow-up outcomes (After propensity score matching).

Author Contributions: C.-L.Y., Y.-C.T. and H.-H.H. designed this study. H.-Y.Y., C.-Y.W. and C.-Y.C. performed the data acquisition. Y.-L.C. and C.-C.H. analyzed and interpreted the data. H.-Y.Y. and C.-Y.T. performed the statistical analysis. C.-L.Y. and Y.-L.C. were major contributors in writing the manuscript. All authors have read and agreed to the published version of the manuscript.

Funding: This study was supported by grants from Chang Gung Memorial Hospital, Taiwan (CORPG3J0591).

Institutional Review Board Statement: Before releasing data to researchers, any information in the database that can identify a particular patient or health care provider is encrypted to ensure privacy. Thus, this study was approved with a waiver of the need for consent from the Institutional Review Board of Chang Gung Medical Foundation (Approval Number: 202100150B1).

Informed Consent Statement: Not applicable.

Data Availability Statement: Not applicable. 
Acknowledgments: The authors thank wish to acknowledge the support and statistical assistance of the Maintenance Project of the Center for Big Data Analytics and Statistics (Grant CLRPG3D0046) and biostatisticians, Hui-Tzu Tu and Yu-Tung Huang, at Chang Gung Memorial Hospital for the study design and monitoring, data analysis, and interpretation.

Conflicts of Interest: The authors declare no financial interests or conflicts of interests.

\section{References}

1. The 4 S Group. Randomised trial of cholesterol lowering in 4444 patients with coronary heart disease: The Scandinavian Simvastatin Survival Study (4S). Lancet 1994, 344. [CrossRef]

2. Hebert, P.R. Cholesterol Lowering with Statin Drugs, Risk of Stroke, and Total Mortality. JAMA 1997, 278. [CrossRef]

3. Holdaas, H.; Fellström, B.; Jardine, A.G.; Holme, I.; Nyberg, G.; Fauchald, P.; Grönhagen-Riska, C.; Madsen, S.; Neumayer, H.H.; Cole, E.; et al. Effect of fluvastatin on cardiac outcomes in renal transplant recipients: A multicentre, randomised, placebo-controlled trial. Lancet 2003, 361, 2024-2031. [CrossRef]

4. Armitage, J.; Bowman, L. Cardiovascular outcomes among participants with diabetes in the recent large statin trials. Curr. Opin. Lipidol. 2004, 15, 439-446. [CrossRef] [PubMed]

5. $\quad$ Baigent, C.; Keech, A.; Kearney, P.M.; Blackwell, L.; Buck, G.; Pollicino, C.; Kirby, A.; Sourjina, T.; Peto, R.; Collins, R.; et al. Efficacy and safety of cholesterol-lowering treatment: Prospective meta-analysis of data from 90,056 participants in 14 randomised trials of statins. Lancet 2005, 366, 1267-1278. [CrossRef] [PubMed]

6. Wanner, C.; Krane, V.; Marz, W.; Olschewski, M.; Mann, J.F.; Ruf, G.; Ritz, E.; German, D. Dialysis Study I. Atorvastatin in patients with type 2 diabetes mellitus undergoing hemodialysis. N. Engl. J. Med. 2005, 353, 238-248. [CrossRef]

7. Fellstrom, B.C.; Jardine, A.G.; Schmieder, R.E.; Holdaas, H.; Bannister, K.; Beutler, J.; Chae, D.W.; Chevaile, A.; Cobbe, S.M.; Gronhagen-Riska, C.; et al. Aurora Study Group. Rosuvastatin and cardiovascular events in patients undergoing hemodialysis. N. Engl. J. Med. 2009, 360, 1395-1407. [CrossRef]

8. Baigent, C.; Landray, M.J.; Reith, C.; Emberson, J.; Wheeler, D.C.; Tomson, C.; Wanner, C.; Krane, V.; Cass, A.; Craig, J.; et al. The effects of lowering LDL cholesterol with simvastatin plus ezetimibe in patients with chronic kidney disease (Study of Heart and Renal Protection): A randomised placebo-controlled trial. Lancet 2011, 377, 2181-2192. [CrossRef]

9. Herrington, W.G.; Emberson, J.; Mihaylova, B.; Blackwell, L.; Reith, C.; Solbu, M.D.; Mark, P.B.; Fellström, B.; Jardine, A.G.; Wanner, C.; et al. Impact of renal function on the effects of LDL cholesterol lowering with statin-based regimens: A meta-analysis of individual participant data from 28 randomised trials. Lancet Diabetes Endocrinol. 2016, 4, 829-839. [CrossRef]

10. Querfeld, U. The clinical significance of vascular calcification in young patients with end-stage renal disease. Pediatr. Nephrol. 2004, 19, 478-484. [CrossRef]

11. Wanner, C.; Amann, K.; Shoji, T. The heart and vascular system in dialysis. Lancet 2016, 388, 276-284. [CrossRef]

12. Foley, R.N.; Parfrey, P.S.; Harnett, J.D.; Kent, G.M.; Murray, D.C.; Pe, B. The Prognostic Importance of Left Ventricular Geometry in Uremic Cardiomyopathy1. J. Am. Soc. Nephrol. 1995, 5, 2024-2031. [CrossRef]

13. Chavers, B.M.; Li, S.; Collins, A.J.; Ca, H. Cardiovascular disease in pediatric chronic dialysis patients. Kidney Int. 2002, 62, 648-653. [CrossRef] [PubMed]

14. Ferris, M.E.; Mahan, J.D. Pediatric chronic kidney disease and the process of health care transition. Semin. Nephrol. 2009, 29, 435-444. [CrossRef]

15. Ku, E.; Mitsnefes, M.M. Cardiovascular disease in young adults with incident ESRD. Nat. Rev. Nephrol. 2019, 15, 390-391. [CrossRef] [PubMed]

16. Diaz-Gonzalez de Ferris, M.E. Adolescents and emerging adults with chronic kidney disease: Their unique morbidities and adherence issues. Blood Purif. 2011, 31, 203-208. [CrossRef]

17. Wong, C.J.; Moxey-Mims, M.; Jerry-Fluker, J.; Warady, B.A.; Furth, S.L. CKiD (CKD in children) prospective cohort study: A review of current findings. Am. J. Kidney Dis. 2012, 60, 1002-1011. [CrossRef] [PubMed]

18. Tsai, T.C.; Chen, Y.C.; Lo, C.W.; Wang, W.S.; Lo, S.S.; Tang, G.J.; Thien, P.F. Incidence and renal survival of ESRD in the young Taiwanese population. Clin. J. Am. Soc. Nephrol. 2014, 9, 302-309. [CrossRef] [PubMed]

19. Ferris, M.E.; Miles, J.A.; Seamon, M.L. Adolescents and Young Adults with Chronic or End-Stage Kidney Disease. Blood Purif. 2016, 41, 205-210. [CrossRef] [PubMed]

20. Modi, Z.J.; Lu, Y.; Ji, N.; Kapke, A.; Selewski, D.T.; Dietrich, X.; Abbott, K.; Nallamothu, B.K.; Schaubel, D.E.; Saran, R.; et al. Risk of Cardiovascular Disease and Mortality in Young Adults with End-stage Renal Disease: An Analysis of the US Renal Data System. JAMA Cardiol. 2019, 4, 353-362. [CrossRef]

21. Kochanek, K.D.; Murphy, S.L.; Xu, J.; Tejada-Vera, B. Deaths: Final data for 2014, national vital statistics reports: From the Centers for Disease Control and Prevention, National Center for Health Statistics. Natl. Vital Stat. Syst. 2016, 65, 1-122.

22. Hsing, A.W.; Ioannidis, J.P. Nationwide Population Science: Lessons from the Taiwan National Health Insurance Research Database. JAMA Intern. Med. 2015, 175, 1527-1529. [CrossRef] [PubMed]

23. Lin, L.Y.; Warren-Gash, C.; Smeeth, L.; Chen, P.C. Data resource profile: The National Health Insurance Research Database (NHIRD). Epidemiol. Health 2018, 40, e2018062. [CrossRef]

24. Roffman, C.E.; Buchanan, J.; Allison, G.T. Charlson Comorbidities Index. J. Physiother. 2016, 62, 171. [CrossRef] [PubMed] 
25. Cheng, C.L.; Lee, C.H.; Chen, P.S.; Li, Y.H.; Lin, S.J.; Yang, Y.H. Validation of acute myocardial infarction cases in the national health insurance research database in Taiwan. J. Epidemiol. 2014, 24, 500-507. [CrossRef]

26. Hsieh, C.Y.; Chen, C.H.; Li, C.Y.; Lai, M.L. Validating the diagnosis of acute ischemic stroke in a National Health Insurance claims database. J. Formos. Med. Assoc. 2015, 114, 254-259. [CrossRef]

27. Xu, S.; Ross, C.; Raebel, M.A.; Shetterly, S.; Blanchette, C.; Smith, D. Use of stabilized inverse propensity scores as weights to directly estimate relative risk and its confidence intervals. Value Health 2010, 13, 273-277. [CrossRef]

28. McCaffrey, D.F.; Griffin, B.A.; Almirall, D.; Slaughter, M.E.; Ramchand, R.; Burgette, L.F. A tutorial on propensity score estimation for multiple treatments using generalized boosted models. Stat. Med. 2013, 32, 3388-3414. [CrossRef] [PubMed]

29. Austin, P.C. Balance diagnostics for comparing the distribution of baseline covariates between treatment groups in propensityscore matched samples. Stat. Med. 2009, 28, 3083-3107. [CrossRef]

30. Goodman, W.G.; Goldin, J.; Kuizon, B.D.; Yoon, C.; Gales, B.; Sider, D.; Wang, Y.; Chung, J.; Emerick, A.; Greaser, L.; et al. Coronary-artery calcification in young adults with end-stage renal disease who are undergoing dialysis. N. Engl. J. Med. 2000, 342, 1478-1483. [CrossRef]

31. Atkinson, M.A.; Lestz, R.M.; Fivush, B.A.; Silverstein, D.M. Comparative clinical outcomes between pediatric and young adult dialysis patients. Pediatr. Nephrol. 2011, 26, 2219-2226. [CrossRef]

32. Efe, D.; Kocaoz, S. Adherence to diet and fluid restriction of individuals on hemodialysis treatment and affecting factors in Turkey. Jpn. J. Nurs. Sci. 2015, 12, 113-123. [CrossRef]

33. Beerendrakumar, N.; Ramamoorthy, L.; Haridasan, S. Dietary and Fluid Regime Adherence in Chronic Kidney Disease Patients. J. Caring Sci. 2018, 7, 17-20. [CrossRef]

34. Prichard, S.S. Comorbidities and their impact on outcome in patients with end-stage renal disease. Kidney Int. 2000, 57, S100-S104. [CrossRef]

35. Chen, Z.; Qureshi, A.R.; Parini, P.; Hurt-Camejo, E.; Ripsweden, J.; Brismar, T.B.; Barany, P.; Jaminon, A.M.; Schurgers, L.J.; Heimburger, O.; et al. Does statins promote vascular calcification in chronic kidney disease? Eur. J. Clin. Investig. 2017, 47, 137-148. [CrossRef]

36. Henein, M.; Granasen, G.; Wiklund, U.; Schmermund, A.; Guerci, A.; Erbel, R.; Raggi, P. High dose and long-term statin therapy accelerate coronary artery calcification. Int. J. Cardiol. 2015, 184, 581-586. [CrossRef]

37. Puri, R.; Nicholls, S.J.; Shao, M.; Kataoka, Y.; Uno, K.; Kapadia, S.R.; Tuzcu, E.M.; Nissen, S.E. Impact of statins on serial coronary calcification during atheroma progression and regression. J. Am. Coll. Cardiol. 2015, 65, 1273-1282. [CrossRef]

38. Ferencik, M.; Chatzizisis, Y.S. Statins and the coronary plaque calcium "paradox": Insights from non-invasive and invasive imaging. Atherosclerosis 2015, 241, 783-785. [CrossRef]

39. De Vriese, A.S. Should Statins Be Banned from Dialysis? J. Am. Soc. Nephrol. 2017, 28, 1675-1676. [CrossRef] [PubMed]

40. Hirota, Y.; Nakagawa, K.; Sawada, N.; Okuda, N.; Suhara, Y.; Uchino, Y.; Kimoto, T.; Funahashi, N.; Kamao, M.; Tsugawa, N.; et al. Functional characterization of the vitamin K2 biosynthetic enzyme UBIAD1. PLoS ONE 2015, 10, e0125737. [CrossRef]

41. Cranenburg, E.C.; Schurgers, L.J.; Uiterwijk, H.H.; Beulens, J.W.; Dalmeijer, G.W.; Westerhuis, R.; Magdeleyns, E.J.; Herfs, M.; Vermeer, C.; Laverman, G.D. Vitamin K intake and status are low in hemodialysis patients. Kidney Int. 2012, 82, 605-610. [CrossRef] [PubMed]

42. Caluwe, R.; Pyfferoen, L.; De Boeck, K.; De Vriese, A.S. The effects of vitamin K supplementation and vitamin K antagonists on progression of vascular calcification: Ongoing randomized controlled trials. Clin. Kidney J. 2016, 9, 273-279. [CrossRef]

43. Krueger, T.; Schlieper, G.; Schurgers, L.; Cornelis, T.; Cozzolino, M.; Jacobi, J.; Jadoul, M.; Ketteler, M.; Rump, L.C.; Stenvinkel, P.; et al. Vitamin K1 to slow vascular calcification in haemodialysis patients (VitaVasK trial): A rationale and study protocol. Nephrol. Dial. Transplant. 2014, 29, 1633-1638. [CrossRef] [PubMed] 